\title{
Portfolio Insurance Strategies by a Large Player
}

\author{
Aymeric KALIFE \\ University Paris Dauphine \& ESSEC Business School
}

December 6, 2004

\begin{abstract}
Market liquidity risk refers to the degree to which large size transactions can be carried out in a timely fashion with minimal impact on prices. Emphasized by the G10 report in 1993 and the BIS report in 1997, it is one factor of destabilization in the financial markets, as illustrated recently by the Asian crisis, the failure of the hedge fund LTCM during the Russian crisis. So in order to assess welfare implications of portfolio insurance strategies, it would be to estimate the dynamic hedging activity in securities markets through a specific parsimonious and realistic model.

In the paper, large traders hold sufficient liquid assets to meet liquidity needs of other traders, and so bear the risk of their imbalanced derivatives portfolio. As a result of their dynamic hedging strategies, through endogenous non-linear positive feedback effects, they buy and sell derivatives at prices shifted by an amount that depends on their net holding. We show how dynamic hedging may directly and endogenously give rise to empirically observed bid-offer spreads, of which we then analyse the two main underlying factors: inventory holding costs and informational asymmetry, thus requiring specific strategic trades in order to tackle portfolio insurance strategy paradox. More specifically we offer partial hedging strategies, such as "feedback volatility" pricing and state-dependent threshold value strategies, illustrating a trade-off between maximizing expected gains and minimizing mis-hedging risk. Moreover we also discuss delicate positions' gamma hedging, which requires creating vega positions in order to profit from the "feedback" volatility, in both long and short term. Finally we model the information asymmetry linked to the specific structure of the options portfolio and devise intertemporal arbitrage strategies for the large player.
\end{abstract}

JEL codes: G11, G12, G21, G22

Keywords: non linear market impact, bid-ask spread, insider trading, transaction costs, state dependent threshold strategies. 


\section{Introduction}

Due to the finite market elasticity in the presence of large traders, the usual continuous delta-hedging strategy may change the equilibrium price dynamics, as was highlighted in the G10 report in 1993 and the B.I.S. report in 1997: "One set of market participants who rely on market liquidity are those firms engaged in dynamic trading strategies, such as dynamic hedging or portfolio insurance. Previous research has highlighted the possibility that such strategies could, at times, have adverse repercussions for market functioning". A very popular dynamic hedging program at that time was portfolio insurance, a dynamic hedging strategy that, as already mentioned, replicates a European put option. These strategies were used to insure security portfolios against a fall in value under a predetermined floor. In theory, they are supposed to protect a portfolio from large depreciations while providing unlimited potential for appreciation. The rapid growth of such programs at that time also has to be seen in the light of portfolio insurance firms aggressively marketing dynamic strategies as a risk management device. These firms specialized in selling dynamic strategies as an alleged substitute for real derivative securities. Lessons learned from the crash teach that synthetic derivatives, in contrast to their real counterparts, may fail to fulfill their promises in practice. One major reason is that typical hedge programs do not incorporate that they themselves, if implemented on a large scale, can cause market conditions they are intended to protect against. This paradox has been widely and increasingly observed since the krach of 1987, and is one factor of destabilization in the financial markets, as illustrated recently by the Asian crisis, the failure of the hedge fund LTCM during the Russian crisis.

It is worth pointing out that the main difference between the stock market crash of 1987 and the crisis in 1998 is the manner in which dynamic hedging became market influencing. In 1987 it was the simultaneous use of portfolio insurance programs by many market participants. In contrast, the nearcollapse of LTCM in 1998 was primarily caused by the high leverage that LTCM built up. Besides this difference the absolute amount of money being dynamically hedged is nonetheless comparable. The severity of the LTCM case is illustrated by the fact that in 1998 assets of LTCM alone totalled 125 billion USD compared to 100 billion USD subject to portfolio insurance schemes in 1987 (the share of portfolio insurance induced selling in the futures markets reached peaks of over $27 \%$ on October 19 and October 20, in the stock market that proportion had reached $15.6 \%$ ). It is also noteworthy that LTCM's off-balance volume in derivatives contracts amounted to incredible 1400 billion USD in notional value.

Market illiquidity is generated by the inability of traders to buy or sell at no cost any quantity according to the definition of Friend and Blume (1975. It refers to the degree at which transaction flows affect asset prices in a market, separately from any change in the economic fundamentals that determine asset values. Thus market liquidity risk is the price risk associated with the executiion

of large transactions quickly, manifested in a sharp movement of prices against a trader involved in a large purchase or sale of a security, or when a trader is 
unable to execute a large trade at a reasonable price. It may be referred as the degree to which large size transactions can be carried out in a timely fashion with minimal impact on prices.

In financial markets it is common that asset prices are pushed in a direction by comparatively large trades. Liquidity or the lack of it causes a combination of transaction costs and a price slippage impact. Firstly, it has an impact on the transaction price: whereas it may be possible to trade small quantities of an asset at the best possible price, which is close to the published mid-price, the larger the trade size the more levels of market depth will have to be tapped and the further the average transaction price will deviate from the mid-price. Secondly, liquidity is directly related to the degree of market slippage: large trades of one agent may remove entire price layers and lead her to adjust prices accordingly.

In order to analyze this market liquidity risk, we distinguish three groups of agents in the market: value investors (or fundamentalists) who hold an asset when they think it is undervalued and short when it is overvalued; trend followers (or chartists) who hold an asset when the price has been going up and sell it when it has been going down; but in the typical case their buy and sell orders do not match, so traders of these two groups enter into contracts with large traders who hold sufficient liquid assets to meet their joint liquidity needs and so provide immediacy by holding stocks and options in inventory to cover imbalances in the buy and sell orders of traders.

As a result large traders, such as financial intermediaries (banks, pension and mutual funds, insurance companies), as observed by Kambhu (1998), sells 50 \% more options than they buy on OTC interest rates option market. This third group of traders absorbs fluctuations in excess demand. But since markets only have limited liquidity, the concentration of sold options among dealers hedging of options affects underlying markets and the value of the option position through "feedback effects", lowering the price when they have to buy and raising it when they have to sell: orders are filled at a price that is shifted from the previous price, by an amount that depends on the net order of traders, to avoid mishedging of their portfolios of derivatives. Such a behavior exaggerates market moves and cause prices to rise above the levels supportable by fundamentals. Large traders may thus move the value of the underlying in an undesired direction because the trade-slippage feeds back into their mark-to-market contract values: buying drives the price up, and selling drives it down.

So in order to assess welfare implications of dynamic hedging, asking whether dynamic hedging is worthy of regulation or not, it would be to estimate the dynamic hedging activity in securities markets. To conduct such an estimation we need a pricing and hedging model of derivatives in imperfectly liquid markets.

Therefore we would like to use a model dealing with these specific dynamic hedging problems in a parsimonious and realistic way, giving rise to consistent bid and offer market prices. To tackle the potential market impact of large transactions on hedging costs, we would also like to devise specific numerical 
hedging strategies complying with usual large traders behaviors. Finally we would like focus on strategies using the insider information of the large trader based on her market power and her portfolio structure. All of these requirements are met by this paper.

The financial market is here characterized by the interaction of one "large trader" whose action affects prices and many price taking "small traders". The usual fundamental characterization of absence of arbitrage Delbaen and Schachermayer (1994) cannot be applied because of market impact function in the underlying asset price dynamics. Therefore Jarrow (1994) find further restrictive conditions required to exclude "Market Manipulation Strategies", i.e. arbitrage opportunities taking the price impact into account. But whereas they considered a symmetric information structure between players, we emphasize here the fact that this equilibrium price is only with respect to the large trader's behavior, given the market impact function and the structure of her portfolio (the number and nature of options she holds). Such an insider information may be in fact used by the large trader to undertake arbitrage strategies. Then, based on this required no arbitrage argument, we can use the analysis developed by Frey (1996) to introduce the positive feedback effects of a continuous dynamic delta hedging strategy by a large trader on the unit option price, giving rise to a non linear Black\&Scholes PDE. This combination of approaches is absolutely required in order to settle an appropriate framework: actually, previous models didn't entail all the required assumptions to give rise to sensible strategies by the large trader.

We describe the financial mechanism behind: whereas among small traders end-user needs in derivatives are roughly balanced across buyers and sellers, large dealers are empirically net writers (sellers) of options, so their exposure to gamma risk is significant, and they have to replicate synthetically the payoff of options by a dynamic hedging self-financing strategy in underlying asset, which bears upper pressures on it, inducing inventory holding costs. And the greater the net demand from the small traders, the higher the market clearing option selling price. The cumulative cost of these "buy high, sell low" hedge adjustments, which equals the value of the option, turns out to be respectively higher than the price-taker B\&S price.

Based on the same principle in the context of a positive net options portfolio, we are able to give rise to a lower buying price. As a result we exhibit a parsimonious endogenous bid-offer spread, through an optimal response from the large trader's dynamic hedging to cover her inventory holding costs and risks. The bid-offer spread is an increasing function of two variables: the size of the large trader's net long or short position in options (the inventory), and the underlying asset price volatility depending on the residual net gamma of her portfolio.We insist here on the endogenous way of obtaining the bid offer spread, in contrast to the usual exogeneous transaction costs methods specifications : such costs here stem directly and endogenously from inventory holding costs. To tes the accuracy of our approach, we first check that such an endogenous bid-offer is consistent with every empirical statistical feature so far observed and we secondly calibrate it to the empirical market bid-offer of a specific option. 
Then we analyse the two main underlying factors of bid-offer spreads, inventory holding costs and informational asymmetry, thus requiring specific strategic trades in order to tackle the dynamic hedging delicate problem.

Firstly we devise specific and realistic partial hedging strategies suitable for such a large trader in order to reduce the inventory holding cost. The first strategy is based on uncertain volatility methods since the portfolio volatility is unknown but capped and floored by the "feedback volatilities", and gives rise to a smaller bid-offer in order to increase P\&L and attract more clients, but to the detriment of a possible weaker hedging ratio, inducing the "mean-variance" arbitrage principle. The second corresponds to the very usual partial hedging situation called "state dependent threshold value strategy" and thus is based on local time criterion. These two strategies used by practitioners are here given with pricing methods which can be implemented very easily.

Secondly, we highlight and the information asymmetry between the large trader and the remaining small traders, which emphasizes the adverse selection cost component of the bid-offer spread. First, the small traders are not precisely aware neither of the reaction function induced by the feedback effect, nor of the amount of options held by the large player. Second, the feedback effect of the large agent's hedging trades induce a "feedback" volatility which is either higher or lower than the usual one. Thus the large player may compensate this gamma hedging cost by trading both the volatility spread (between realized and implied volatility) and vega convexity. Third, the previous price of a derivative asset is equal to the hedge cost only with respect to the large trader's information, i.e. with respect to her portfolio structure and imbalance position, to the detriment of the small traders who become aware only afterwards.

Actually, due to her inventory holding costs, the large player may suffer a lot from rebalancing her hedging position, especially in case of short gamma positions (which is often empirically observed in the long term), although in part reduced thanks to the selling high feedback volatility. But she is the only one who precisely knows the feedback effects of her own hedging strategy, inducing "feedback" volatilities that are either higher or lower than the usual one. Therefore she may use such an insider information to handle her gamma position by trading the volatility spread (between realized "feedback" and implied volatility) in the long term, and buying vega convexity through combinations of derivatives in the short term.

Because her trades influence the underlying asset price and so the option price, she is likely to exploit this informational advantage through portfolio hedging strategies to the detriment of the small traders, trying to remain undiscovered at the same time. This information asymmetry can be modellised by the notion of initial filtration enlargement, based on a greater information on the intrinsic underlying asset dynamics at the large trader's disposal from the option signature time: she doesn't hedge any longer as the option expires, she is perfectly aware of both the structure of her portfolio and the feedback hedging effects. We derive arbitrage spreads and give various realistic financial examples 
of intertemporal portfolio strategies to the profit of the large trader, in the case of full and increasing information asymmetry. The large trader is motivated to trade not only by trading profits but also by a desire to protect the value of their inventory and disguise the quality of the information underlying their trades. So she adopts inconspicuous strategies in order to camouflage her trades. Then she may use several types of strategic hedging in trading European and American options, using the maturity effect, the simultaneous and separate negotiations with different small traders, and the relative situation of the underlying asset price with respect to the strike.

Thus we have developed an approach generating illiquidity as an endogenous trading cost from the inability of traders to share a common risk perfectly.

The rest of this paper is as follows. In section 2 we introduce the framework of our analysis and the corresponding pricing and hedging of derivatives, taking into account hedging feedback effects. In Section 3 we introduce an endogenous bid-offer spread stemming from those inventory holding costs, consistent with market data and implied volatility smiles, and then develop specific hedging strategies: on the one hand two partial hedging strategies, on the other hand to compensate the losses in gamma hedges through vega trading and to profit from the information asymmetry about the feedback effects and the structure in maturities and strikes of the large trader's options portfolio. Section 4 contains concluding comments.

\section{The Market Structure Setting}

\subsection{Framework and assumptions required for pricing and hedging in the presence of a large trader}

The financial market is characterized by the interaction of one "large trader" whose action affects prices and many price taking "small traders". The framework of our analysis is based on a continuous-time version of the models proposed by Jarrow (1994), further developed by Frey (1996), but no previous model entails all the required assumptions to give rise to sensible strategies by the large trader. Moreover we emphasize that our framework holds only with respect to the large trader's information who is the only one who knows the number of hedged options, which highlights the information asymmetry between the large trader and the small traders on the market. For simplicity of the argument, we assume the risk-free interest rate is zero.

A1: There are no transaction costs and no short sale restrictions.

A2: Equilibrium price and the reaction function

The observed underlying asset price on the market $\tilde{S}_{t}$ can be expressed as a function $\psi$ called "reaction function" $\tilde{S}\left(t, S_{t}, \alpha_{t}, \gamma_{t}\right)=\psi\left(t, S_{t}, \alpha_{t}, \gamma_{t}\right)$ where $S_{t}$ is the underlying price in the absence of the large trader. $\alpha$ is the large trader's position (cadlàg, whose jumps are bounded below, and such that $\alpha_{t}^{+}=\lim _{s \rightarrow t} \alpha_{s}$ is a continuous semimartingale) in the underlying and $\gamma$ the number of options 
held by the large trader. $\psi$ is assumed to be smooth enough on $[0, T] \times R^{+} \times I_{0} \times I_{1}$ where $I_{0}$ and $I_{1}$ are open intervals.

A3: The large trader has a procyclical market power: $\frac{\partial}{\partial \alpha} \psi>0$

A4: The underlying asset price process is independent of the large trader's past holdings. If $\alpha^{t}=\left(\alpha_{t}, \alpha_{t-1}, \ldots, \alpha_{0}\right)$ represents the history vector for $\alpha$, $\tilde{S}\left(t, S_{t}, \alpha^{t}, \gamma_{t}\right)=\psi\left(t, S_{t}, \alpha_{t}, \gamma_{t}\right)$

A5: Underlying asset price dynamics $d \tilde{S}_{t}=\sigma_{t} \tilde{S}_{t} d W_{t}+\rho_{t} \lambda\left(\tilde{S}_{t}\right) \tilde{S}_{t} d \alpha_{t} \cdot \lambda_{t}(S)$ is a continuous function called 'market liquidity profile', used to retrieve a particular shape of the implied volatility smile. $\rho_{t}$ represents the intensity of the liquidity impact (a possible choice is the ratio of change in the price of the underlying to notional traded, which is observable given an order book). So $\frac{1}{\rho \lambda_{t}\left(\tilde{S}_{t}\right) \tilde{S}_{t}}$ represents the market depth at time $t$, the order flow required to move prices by one unit.

In our context, the fundamental characterization of absence of arbitrage Delbaen and Schachermayer (1994) cannot be applied because of the direct feedback effect in the underlying asset price dynamics. An alternative "no arbitrage condition", called "No Market Manipulation Strategy" (MMS) by Jarrow (1994) is introduced and based on paper wealth (the value of the portfolio when prices are evaluated using the large trader's current holdings).

A6: There exists an equivalent martingale measure for the underlying asset in the absence of the large trader

A7: The market operates in the absence of corners, that is the combined

effective holding of the underlying and the derivative must not exceed the net supply of the underlying asset.

A8: Synchronous Markets Condition $\psi\left(t, \alpha_{t}+\gamma_{t} \cdot \xi_{t}, 0\right)=\psi\left(t, \alpha_{t}, \gamma_{t}\right)$ where $\xi_{t}$ is any admissible self-financing replicating strategy ('delta') in underlying assets. This amounts to saying that prices adjust instantaneously across underlying and derivative markets (i.e. price changes in one should be immediately reflected in the other). Otherwise the large trader may use information mismatches between them to post riskless profits.

Finally we introduce the notion of Market Manipulation Strategies with respect to the information of the large trader (the structure of her portfolio), based on real wealth:

$$
\begin{aligned}
V_{0} & =0 \\
V_{T} & \geq 0 \text { a.s. } \\
P\left[V_{T}>V_{0}\right] & >0
\end{aligned}
$$

Proposition 1 Under conditions A1-A8, and given the number of options $\gamma_{t}$ held by the large trader at time $t$, and assuming $c \leq \alpha_{t}+\xi_{t} \gamma_{t}$ where $c \in[-\infty, 1]$ there is no MMS in real wealth.

Proof. The proof is done in the dicrete case then extended to the continuous framework through convergence results. We use the self financing property 
then the definition of real wealth in order to show that the No MMS condition is enforced. Details can be found in Propositions 3.10 and 3.23 of Bierbaum (1997).

\subsection{Pricing and dynamic hedging with respect to the large trader's information}

\subsubsection{The notion of positive feedback effects from the large trader's hedging portfolio strategy on the option price}

In order to maintain an option portfolio's exposure to price risk, the large trader must adjust the hedge position after a price shock to allow for the change in the option's price sensitivity. More precisely, a call option's value increases by an amount smaller than the increase in the value of the underlying asset because there is always some probability that the price of the underlying asset will reverse direction by the time the contract matures, and even fall below the strike price at expiration, rendering the option worthless. But as the underlying asset's price rises further, however, this probability of a worthless outcome becomes smaller, and the option's value becomes more sensitive to changes in the underlying asset's price. To compensate for this increase in the price sensitivity of a call option, a hedge position in the underlying asset must be made larger as well, affecting in return its price process. This mechanism generates the potential for positive feedback in price dynamics because the hedge adjustment is to buy (sell) the underlying asset after its price rises (falls), as the transactions could introduce further upward (downward) pressure on prices after an initial upward (downward) shock to asset prices.

\subsubsection{The underlying asset dynamics in the presence of the large trader}

The large trader's portfolio strategy, denoted $\phi$, is assumed to be $C^{1,2}\left([0, T] \times R^{+}\right)$ and $\rho \tilde{S} \phi_{S}(t, \tilde{S})<1 \forall(t, \tilde{S}) \in[0, T] \times R^{+}$.

Proposition 2 The portfolio strategy in the underlying assets is denoted

$$
\begin{aligned}
\alpha_{t} & =\phi\left(t, \tilde{S}_{t}\right) \\
d \tilde{S}_{t} & =v\left(t, \tilde{S}_{t}\right) \tilde{S}_{t} d W_{t}+b\left(t, \tilde{S}_{t}\right) S_{t} d t
\end{aligned}
$$

with "adjusted" trend and "feedback" volatility coefficients :

$$
\begin{aligned}
v\left(t, \tilde{S}_{t}\right) & =\frac{\sigma_{t}}{1-\rho \lambda\left(\tilde{S}_{t}\right) \tilde{S}_{t} \phi_{S}(t, S)} \\
b\left(t, \tilde{S}_{t}\right) & =\frac{\rho \lambda\left(\tilde{S}_{t}\right)}{1-\lambda \rho \tilde{S}_{t} \phi_{\tilde{S}}(t, \tilde{S})} \times\left(\phi_{t}(t, \tilde{S})+\frac{\sigma_{t t}^{2 \tilde{S} 2} \phi_{S S}(t, \tilde{S})}{2\left(1-\rho \lambda\left(\tilde{S}_{t}\right) \tilde{S}_{t} \phi_{S}(t, \tilde{S})\right)^{2}} 2\right)
\end{aligned}
$$


Proof. We apply the usual continuous delta hedging strategy used by Black \& Scholes. Details can be found in Frey (1996).

Once again we emphasize that the large trader is the only aware of the specific feedback effect intensity on the option price.

\subsubsection{Perfect replication of a European call option by the large trader}

We consider a usual continuous delta-hedging strategy implemented by the large trader. For simplicity of notation, we assume the risk-free interest rate is zero.

Proposition 3 Under a zero risk-free interest rate (for simplicity of notation), the replicating cost of a $\gamma$-option portfolio is the solution of this quasi-linear $P D E$

$$
\left\{\begin{array}{c}
u_{t}(t, S, \gamma)+\frac{1}{2} \frac{1}{\left(1+\rho \lambda(S) S u_{S S}(t, S, \gamma)\right)^{2}} \sigma_{t}^{2} S_{t}^{2} u_{S S}(t, S, \gamma)=0 \\
u(T, S, \gamma)=n h(S)
\end{array}\right.
$$

where $\alpha(t, \tilde{S}, \gamma)=\phi(t, \tilde{S}, \gamma)=-u_{S}(t, \tilde{S}, \gamma)$ is the replication of the option portfolio continuous delta hedging strategy and $V_{t}=u(t, \tilde{S}, \gamma)$ is the replicating value of a $\gamma$ European call portfolio held by the large trader whose final payoff is $h\left(S_{T}\right)$ at time $T$ per option unit.

Proof. The existence and unicity of the solution of the above quasi-linear PDE with its terminal value was proved by Frey (1998) (equation 3.22).through a quasilinear PDE.

Solving such a non linear PDE requires distinguishing long and short positions the sign of the payoff depending on whether the large trader buys or sells options: for a short call we have

$$
u(T, S, \gamma)=-\gamma(S-K)^{+}
$$

whereas for a long call

$$
u(T, S, \gamma)=\gamma(S-K)^{+}
$$

so long and short positions have different values (see later).

Proposition 4 Given the number of options $\gamma_{t}$ held by the large trader at time $t$, and under the assumptions A1-A9, we consider an admissible self-financing hedging portfolio strategy $\xi=(\alpha, \beta, \gamma)$ which replicates the derivative, the value of which is denoted by $V^{\xi}$. Then the MMS condition (with respect to the large trader's information) implies

$$
V_{t}^{\xi}=c_{t}
$$

Proof. We consider a variation in hedging positions and work out the terminal wealth, using the Synchronous Markets Condition. Finally the MMS condition implies the result. Details can be found in Proposition 3.3. of Frey (1996). 
The feedback effect of the large trader's dynamic hedging portfolio strategy on the unit call option price Generally speaking, an option can be hedged by taking an offsetting position in the underlying asset, and the required size of this position varies with the price of the underlying asset. This variability of the hedge position results from the varying sensitivity of the option value to the price of the underlying asset as its price changes. Simulations illustrates the fact that when the large trader sells European call option, the European call unit price rises:

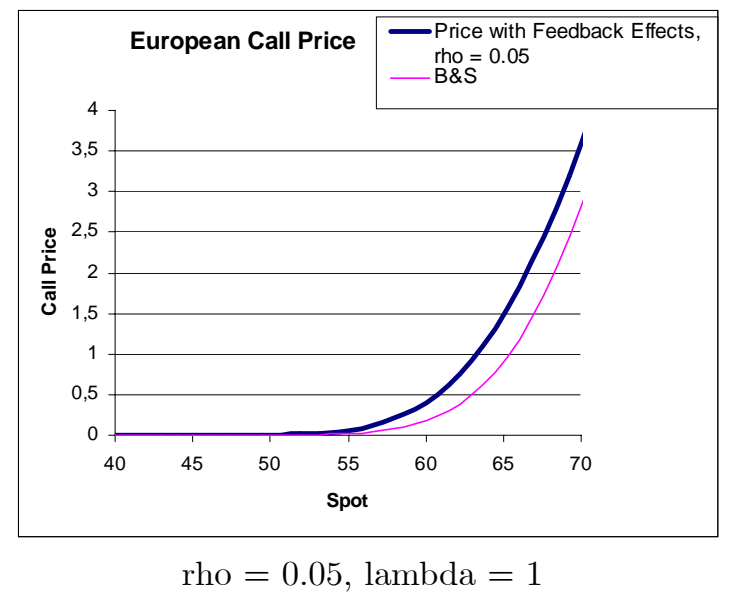

Therefore an apparent paradox arises empirically observed on the markets as regards large traders' transactions: selling a large amount of calls causes the price to rise.

In order to explain financially such a mechanism, let's analyze the following steps. Actually, as the large trader sells European calls, she has to buy a large amount of the underlying asset in order to hedge, which makes the underlying asset price rise, thus the short delta decreases, implying a short gamma, so the 'feedback'volatility $\left(\frac{\sigma_{t}^{2}}{\left(1+\rho \lambda(S) S u_{S S}(t, S, \gamma)\right)^{2}}\right)$ rises. Consequently the option unit price turns out to be higher than the usual price-taker B\&S price.

Therefore illiquidity appears as an endogenous trading cost compensating for the sharing of risks measured here by the spot market volatility. Actually, buying with rising prices, the large trader's demand is procyclic. Therefore, the apparent paradox is just a consequence of the positive feedback effect induced by the dynamic hedging of the large trader through its Portfolio Insurance Strategy, designed to protect the capital during a market downturn by replicating option positions. In fact, this positive feedback effect stems from the absence of sufficient natural counterparts to meet the demand for puts and calls, where large dealers can meet the demand by selling puts and calls. In doing so, they become short the option; so they can neutralize their net risk exposure by synthetically replicating long option positions, which requires selling as the market falls and buying as it rises, to ensure the hedge position is sufficient to cover the 
option rising exposure, which introduces transactions large enough to amplify the initial price shock.

Some observers cite the stock market crash of 1987 - which occurred in the absence of any significant change in economic fundamentals - as an example of positive feedback dynamics: the sharp fall was intensified by portfolio insurance strategies that prescribe the sale (purchase) of stocks when prices fall (rise). These mutually reinforcing interactions are characteristic of markets where traders have short decision horizons, or where they operate under external constraints on their decision (due to internally imposed trading limits or under risk management system which circumscribes their actions), which may require positions to be sold for cash when net asset values are low or when a margin call dictates liquidation of trading positions. More recently, the dynamic hedging associated with OTC puts has been blamed for several bouts of market instability, notably in 1989, 1991,1997, and 1998. Furthermore, program trading, most commonly used by large traders, currently constitutes about 10 percent of a typical day's volume on the NYSE.

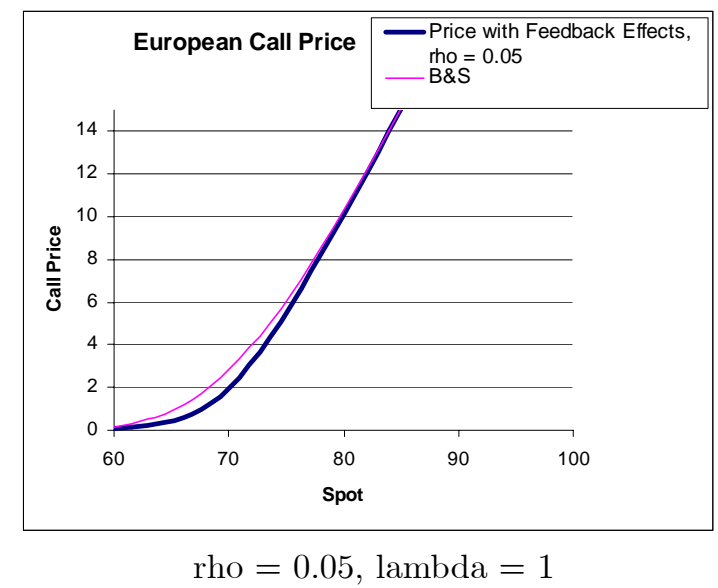

Symmetrically, as the large trader buys European calls, she has to sell a large quantity of the underlying asset in order to hedge, which makes the underlying price and its volatility fall, as shown by the PDE (see above), so the option unit price (because the vega of a call is positive) becomes smaller than the usual price-taker B\&S price.

The unit option price depends on the total amount of options replicated by the large trader For the simplicity of simulations, we take $\rho \lambda(S)=$ $\frac{\phi}{S}$ where $\phi$, assumed to be constant, represents the volume effect on the unit underlying price. We illustrate here the non homogeneity of prices: the larger the absolute payoff, the wider the relative bid-offer spreads, since the reaction function is super linear. We show through simulations that the feedback effect of the large trader's activity causes the hedge cost to be non-linear in the number of replicated options: the price of the large trader's replicating portfolio (and thus 
the equilibrium option price) is not proportional to the number of options held by the large trader. In fact, the option unit price increases with the number of options held by the large trader. Therefore, in finitely elastic markets the pricing argument from the standard theory doesn't work any longer. More precisely, as illustrated below, the average replicating cost is nearly a quasi-linear function of the number of options held, which implies that the replicating unit price is roughly a quadratic function of the number of options held by the large trader.

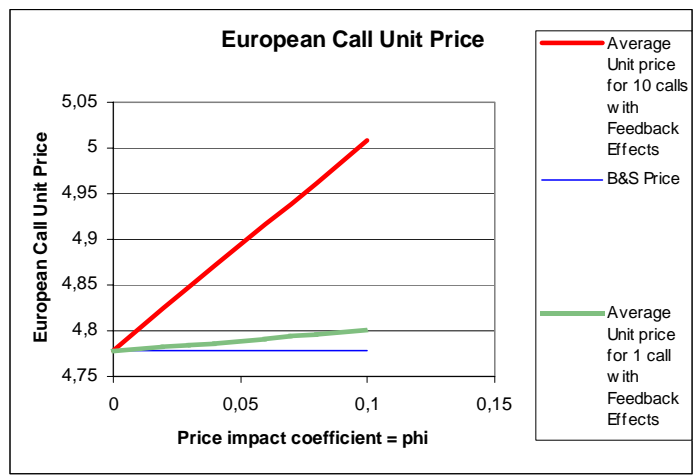

Unit 10-call versus 1-call price

As a result, the number of options held by the large trader has an impact on the unit price of the call. But, except the large trader, and maybe her broker, no other trader is aware of this information. So the large trader is the only one who precisely knows the dynamics of the underlying price. Therefore she can use this information asymmetry in order to manipulate prices.

\section{Dynamic Hedging Stategies by a Large Player}

\subsection{The inventory holding cost component of the option bid-offer spread}

Because the large player will buy low and sell high through the feedback effect from her dynamic hedging strategy, a bid-offer spread for derivatives endogenously naturally arises, serving as a revenue source as well as a risk insurance buffer. Furthermore large imbalances through higher hedging ratios lead to price movements and to an increase in volatility, which increases the offer-price and 
decreases the bid-price, so widen the bid-offer spread.

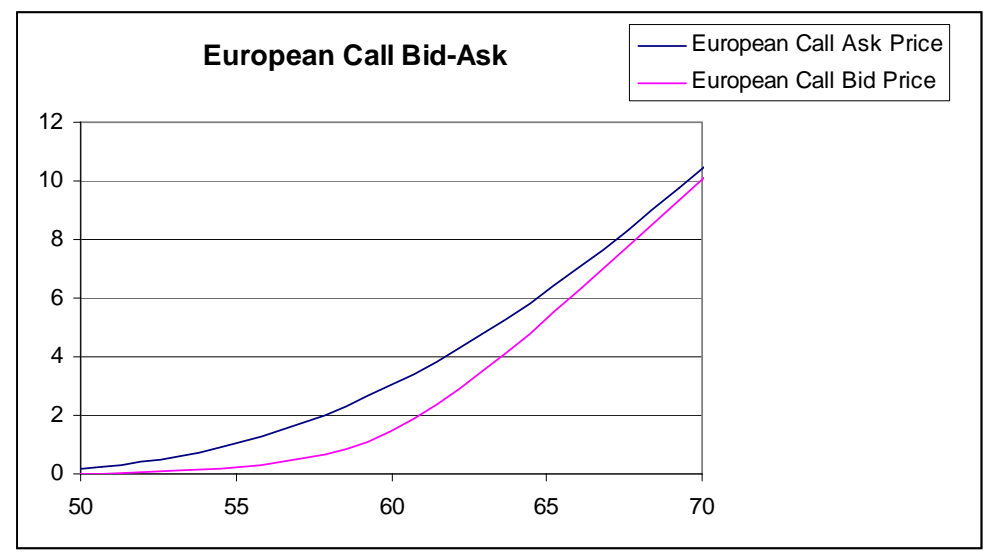

Therefore we can compare large players with market makers, and we thus prove the emergence of market makers as a natural phenomenon in financial markets. In fact, most of the participants in the OTC bond market are large traders (dealers) who trade on behalf of their institutional clients, and who essentially act similar to market makers in the stock market: acually, the large trader has a discretion any choice with respect to the timing and the price of the trade, i.e. decides whether an issue is worth buying at a particular price or not.

Traditionally, the large player is characterized as accepting orders to buy and sell an option at the bid and ask prices which are adjusted to cover her average costs. The bid-offer spread provides the large player with compensation for the risk of her or her hedging activities. A number of theoretical models specify the cost component of the large player's bid-offer spread. Stoll (1978) and Stoll (1989) posit that large player's costs fall into three categories: order-processing costs, inventory-holding costs, and adverse selection costs. The first category costs are largely fixed, at least in the short run, and their contribution falls with the trading volume, so we will neglect them in our setting. The second category, inventory holding costs, are the costs that a large player incurs while carrying positions acquired in supplying investors with immediacy of exchange (i.e. liquidity). If the net position in derivatives is non zero, the large trader can hedge the value of their options inventory using underlying assets. In fact, in the absence of sufficient natural counterparts to meet the demand for puts and calls, large dealers meet the demand by selling puts and calls, which increases the size of their net inventory. They can neutralize their risk exposure by synthetically replicating option positions. These costs of hedging the inventory need to be covered by the revenues from market making, i.e. by the bid-offer spread, and they will depend both on the size of the inventory and on the price-change in the derivative (the higher the price-change risk, the higher the bid-offer spread). Thus, the premium embedded in the bid-offer spread covers the hedging costs the large trader expects to face while the option is held in inventory: the large trader wants to be compensated for hedging costs associated with the option 
inventory imbalances, which are inherently large when buying or selling large quantities of options. And limiting inventory holding risk cost is all the more a key issue that the large trader is short gamma, characterizing a procycling behavior (buys high, sell low), especially when the underlying asset price evolves inside a corridor.

Nevertheless, the large trader limits its dynamic replication to its residual exposure (net gamma), not to its gross exposure. So this form of intermediation relies on the ability of large dealers to manage their risks dynamically. The option Bid-Offer spread accounts for the residual exposure replication cost: it equals zero if the large player options inventory is balanced, and increases with the number of replicated options. Furthermore, as shown below, this replicating cost is growing more than proportionally with respect to the number of replicated options, which describes the compensation of bearing price risk associated with an increasing constraint on the large player as her inventory is less and less balanced. This explains the widening bid-offer spread as the number of replicated options increases. This is consistent with Vijh (1990) who reports that large option trades cause a widening of the bid-offer spread in the option market.

As a result the bid-offer is derived in part as the result of the large trader's optimized hedging behavior. The principal result then is that the bid-offer spread is an increasing function of two variables: the size of the large trader's net long or short position in options, and market price volatility. Kim, Ko and Noh (2000) show that in general inventory costs, the holding of undesired risky positions, account for a very large proportion of the bid-offer spread, so that transaction costs come from the trader's inability to share risk freely with the rest of the futures market.

The other essential component of the bid-offer spread is linked to the third category of large player costs, the adverse selection costs, which are presented in section 5 .

\subsubsection{A parsimonious endogenous bid-offer spread consistent with market data}

Therefore, the hedging strategy of a large trader naturally induces the empirically observed strictly positive and asymmetric spread between bid and ask prices, linked to the degree of market liquidity, which leads to the comparison of the large trader with a large player or supplier of liquidity, requiring a premium for liquidity services. As a result, we account for bid-offer spreads endogenously, and not exogenously, as articles on transaction costs do, stemming here directly from the limited market depth and the hedging behaviour of large players. In order to test the accuracy of our approach, we look at several key issues such as pricing errors, volatility smile and bid-offer spread statistical features.

First we show that such a model improves pricing. We use IBM call options traded on the CBOE during 1995, assuming that all option writers use delta hedging, to estimate the implied model effect parameter $(\lambda \rho)$ of the total large trader, whose stock holding is the aggregate hedging position of all option writ- 
ers, i.e. the number of written options.. The risk free rate is assumed to be $3 \%$, approximating the rate on the month treasury bill during 1995 .

$$
\mathbb{E}[\lambda \rho]=0.30
$$

and the average square error equals 0.57 .

Second, such a complete market model is likely to give rise to a realistic implied volatility smile due to the random "feedback" volatility. Financially speaking such an anomaly has often been linked to the net buying pressure of calls and puts used for hedging purpose, in accordance with liquidity features: in a downward trending market liquidity is usually with far more large moves. Thus the large player's hedging activity may play quite a significant role. Taking $\rho \lambda(S)=\frac{\phi}{S}$ gives rise to a skew

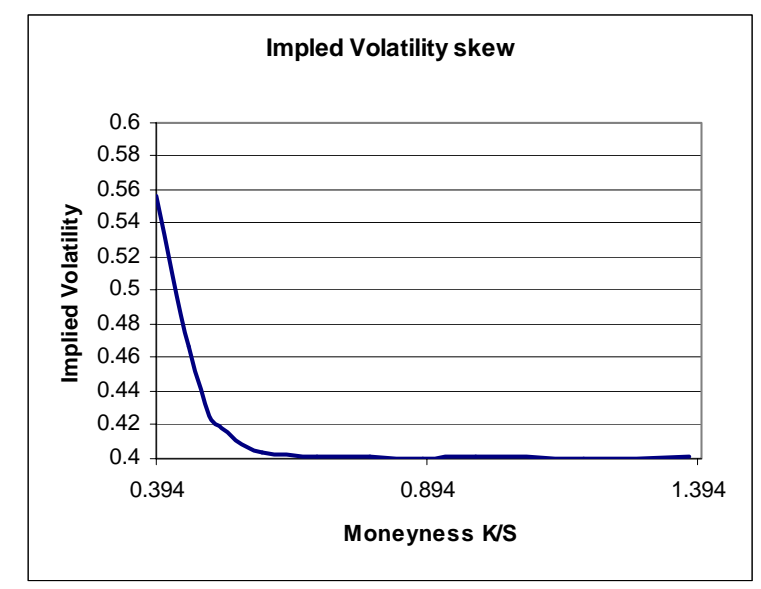

In order to get various and flexible "smirk" profiles we specify the function $\lambda(S)$ by taking a decreasing function, with a minimum around the forward price $S_{0}$, and $\lambda(S)>>1$ for $S$ if very small compared with $S_{0}$

$$
\lambda(S)=1+\left(S-S_{0}\right)^{2}\left(a_{1} 1_{\left\{S \leq S_{0}\right\}}+a_{2} 1_{\left\{S \geq S_{0}\right\}}\right)
$$

Based on S\&P 500 index call options from July to December 1990, we work out $\rho, a_{1}, a_{2}$ in roder to fit options prices, thus

$$
\begin{aligned}
\rho & =0.017 \\
a_{1} & =0.236 \\
a_{2} & =0.007
\end{aligned}
$$

From this we get the implied volatility smile through the Raphson-Newton al- 
gorithm

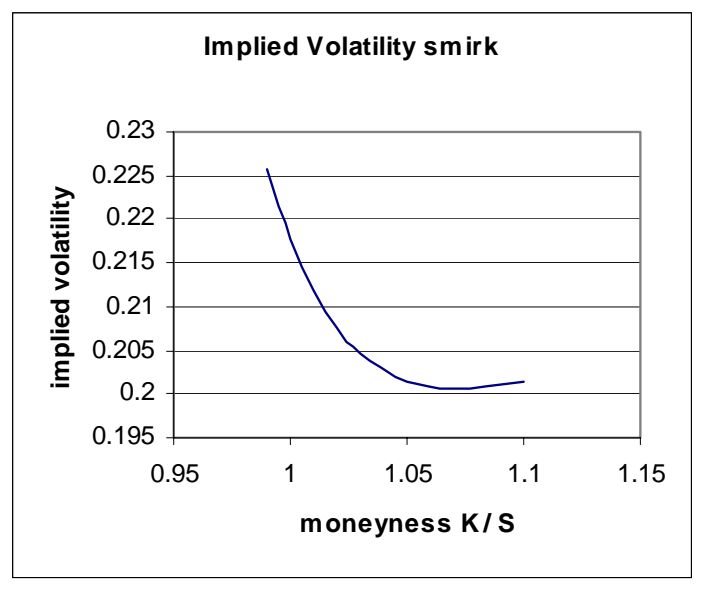

Whereas most models obtain the smile by exogenously altering the volatility structure of the underlying price process, such as Stochastic Volatility or ARCH models, here no assumptions are needed regarding the underlying price volatility, the smile pattern rather occurs endogenously as a consequence of the market structure. Kalife (2003) exhibits further development about implied volatility smirks due to the hedging of the large player, through the introduction of a stochastic volatility.

Third, our model is consistent with every empirically observed statistical feature of bid-offer spreads, see for instance Chan and Chung (1999):

- the bid price is strictly higher than the ask price, and the spread between B\&S and bid prices is higher than the spread between Black \& Scholes and ask prices: the option value is closer to the bid than to the ask quote. This illustrates the fact that the market impact of buying and selling are different.

- the higher the underlying asset price, the greater the investment in inventory, the higher the carrying cost, and the higher the spread; besides the larger the liquidity parameter $\rho$, the lower the liquidity for the market of the underlying, and the wider the relative bid-offer spreads for the derivative.

- The option value is closer to the bid than to the ask quote and the degree of the asymmetry increases as the moneyness of the option decreases or 
increases:

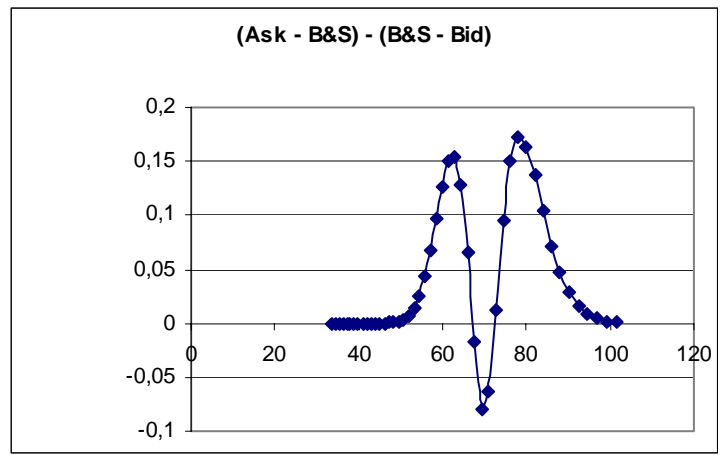

- The ask quote changes more than its bid quote, the same for their standard deviations and the standard deviations of their changes

- The ratio of theses two quotes and of their changes are also in accordance with empirical facts: the slope coefficients decline as the moneyness $(\mathrm{S} / \mathrm{K}$ for calls) of the options declines

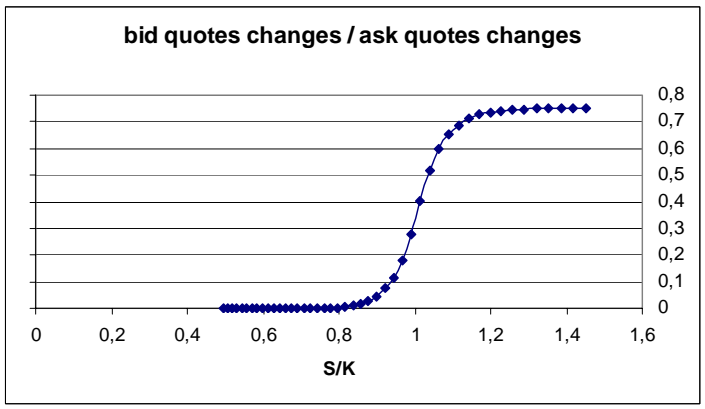

- Both Quotes Standard deviations decrease w.r.t. K/S for a call

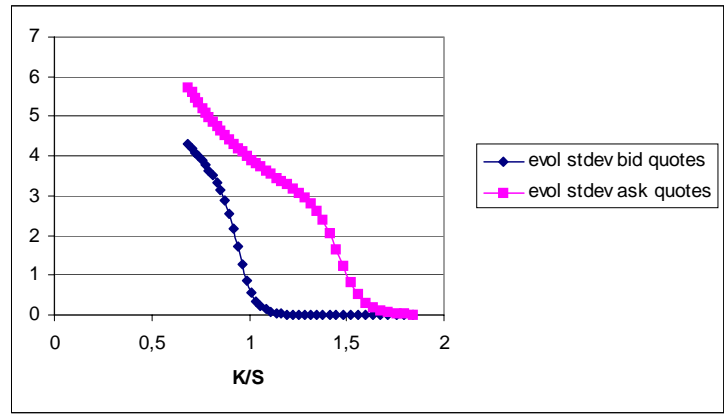

whereas it increases for puts. So the more out-the-money an option is, the less variable its value, thus implying a volatility smile. 


\subsection{Reducing inventory holding costs through strategic partial dynamic hedging}

\subsubsection{Feedback volatilities dynamic hedging strategies}

The Bid-Offer spread accounts for the impact of the net exposure hedging cost on ask and bid prices. Of course, if the large player 's book is strictly balanced (with exact opposite positions on the buy and the sell side, ie including the same derivatives characteristics such as strikes, maturities), which implies a zero net exposure, then the large player is able to buy and sell as any other small trader. Otherwise, she has to minimize the bid-offer spread, in order to attract more customers, while keeping a reasonable hedging ratio. Thus illiquidity will be generated as an endogenous trading cost from the inability of traders to share a common risk perfectly. Moreover, reducing hedging costs is all the more needed that the volatility:used to hedge a selling (deriving a short gamma position) is the highest one, whereas the one used to hedge a buying (inducing a long gamma position) is the lower one, which is the worst scenario as regards the P\&L.

Therefore, it may be profitable to consider the whole portfolio of her various derivative products, instead of hedging every derivative separetly, giving access to a narrower bid-offer spread through diversification, so to better prices and thus to more customers, but to the detriment of the hedging ratio. Nevertheless, since the portfolio of the book of the large player is not quoted on the market, the large player is not able to know its implicit volatility which is uncertain. That's why she may use the two "positive feedback" volatilities developped in the previous part of our article: one, higher than the usual (i.e. used for price takers) volatility, corresponds to the Offer price, and one, lower than the usual volatility, to the Bid price. But this time we use the higher feedback volatility as the gamma position is negative, and the lower as the gamma position is negative, which is the best scenario as regards the P\&L.

In order to illustrate, we consider the example of a book composed of two calls with different strikes: the large trader is long one call of strike $K_{1}$ and short another of strike $K_{2}$ with $K_{1}<K_{2}$. This amounts to pricing a call spread. Due to the convexity of the call payoff and the regularity of the volatility function, the price function is also convex, which implies a lower bid price and a higher ask price than the usual hedging price. If we call $\sigma^{+}$the upper "feedback" volatility (relative to the selling of a call) and $\sigma^{-}$the lower one (relative to the buying of a call), $p_{t}$ the unit call price, the sum of the hedging ratios of the two calls is

$$
\Delta(t)=\frac{\partial^{2}}{\partial s^{2}} p_{t}\left(S_{t}, K_{1}, \sigma^{+}\right)-\frac{\partial^{2}}{\partial s^{2}} p_{t}\left(S_{t}, K_{2}, \sigma^{-}\right)
$$

If now we consider the global portfolio hedging ratio, we have to notice that the call spread payoff is neither convex nor concave. But taking into account the changing convexity of the global portfolio, and using the corresponding "feedback volatilities" the global hedging cost is getting lower than considering 
the sum of the hedging ratios of the calls.

$$
\left\{\begin{array}{c}
\frac{\partial}{\partial t} p_{t}^{\gamma}(s)+\frac{1}{2} \frac{\partial^{2}}{\partial s^{2}} p_{t}^{\gamma}(s) \gamma^{2}(t, s) s^{2}=r p_{t}^{\gamma}(s) \\
\gamma(t, s)=\left\{\begin{array}{c}
\sigma^{+} \text {si } \frac{\partial^{2}}{\partial s^{2}} p_{t}^{\gamma}(s) \geq 0 \\
\sigma^{-} \text {si } \frac{\partial^{2}}{\partial s^{2}} p_{t}^{\gamma}(s)<0
\end{array}\right. \\
\left(s-K_{1}\right)^{+}-\left(s-K_{2}\right)^{+}=p_{T}^{\gamma}(s)
\end{array}\right.
$$

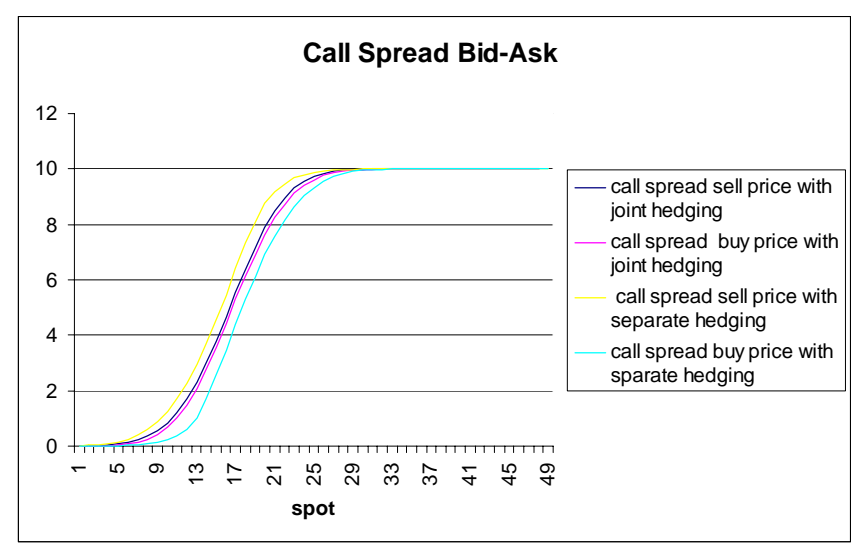

Thus we illustrate the narrowing of the bid-offer, which implies lower transaction costs and the access to more customers, but to the detriment of a weaker hedging ratio (or a higher hedging error).

In fact, if $\Delta$ is the portfolio global hedging ratio, the hedging error equals the difference between the two separate prices:

$$
\begin{aligned}
d e_{t} & =\frac{1}{2} \frac{\partial^{2}}{\partial s^{2}} p_{t}^{\gamma}(s) s_{t}^{2}\left(\gamma_{t}^{2}-\sigma_{t}^{2}\right) d t+\sigma_{t} s_{t}\left[\Delta(t)-\frac{\partial}{\partial s} p_{t}^{\gamma}(s)\right] d W_{t} \\
e_{t} & =\frac{1}{2} \int_{0}^{T} \frac{\partial^{2}}{\partial s^{2}} p_{t}^{\gamma}(s) s_{t}^{2}\left(\gamma_{t}^{2}-\sigma_{t}^{2}\right) d t+\int_{0}^{T} \sigma_{t} s_{t}\left[\Delta(t)-\frac{\partial}{\partial s} p_{t}^{\gamma}(s)\right] d W_{t}
\end{aligned}
$$

Because of the definition of $\gamma_{t}$, the term $\frac{\partial^{2}}{\partial s^{2}} p_{t}^{\gamma}(s) s_{t}^{2}\left(\gamma_{t}^{2}-\sigma_{t}^{2}\right)$ is always positive. However the sign of the second term, $\sigma_{t} s_{t}\left[\Delta(t)-\frac{\partial}{\partial s} p_{t}^{\gamma}(s)\right] d W_{t}$, is unknown. Therefore we are not able to know ex-ante the sign of the hedging error, and so we can't easily compare the gain in a narrower Bid-Offer spread to the risk incurred by a partial hedging strategy. Nevertheless this uncertain trade-off corresponds to the usual mean/variance approach. As a result, such strategies give rise to a trade-off between expected gain, by reducing the bid-offer spread and thus transaction costs, attricting more clients and thus fees, and risk (through a weaker hedging ratio).

\subsubsection{State dependent threshold value dynamic hedging strategies}

With a brief interruption in mid-1997, the yen depreciated vis-à-vis the dollar by some 40 percent during from 1995 to 1998 and reached an eight-year low at 
$¥ 147.26$ per dollar on August 11, 1998. This long-running appreciation of the dollar was abruptly and sharply reversed in the wake of renewed turbulence in emerging markets. Of particular interest are the developments surrounding the unprecedented, sharp appreciation of the yen during October 6-9, 1998, when the yen appreciated 15 percent vis-à-vis the dollar. This episode was driven by a confluence of factors- some of a fundamental nature, others largely technical but generating positive feedback dynamics. Actually the initial spate of dollar selling, in the wake of some turbulence in U.S. markets and the cut in interest rates by the Federal Reserve, may have induced a change in sentiment that the dollar's long-standing strengthening vis-à-vis the yen had run its course. The impression of a turning point was reinforced by indications of a cascade of dollar selling by institutional investors, including hedge funds. Large financial institutions were reportedly unwinding their yen-carry trade positions. According to market participants, technical factors stemming from standard hedging procedures may have contributed to the sudden surge in the yen.

The timing and the speed of the exchange rate changes strongly suggest that short-term trading conditions (such as the large-scale unwinding of "yencarry trades") and technical market factors (including repercussions from the expiration of barrier options) contributed significantly to the sharp dynamic adjustments in the yen/dollar market. In fact large dollar-yen movements were likely exacerbated by stop-loss orders and, more important, by the cancellations of barrier options and the unwinding of associated hedging positions by dealers, sych as knockout options because they are less expensive than standard options. The volume of outstanding yen foreign exchange contracts had grown at end-June 1998 to $\$ 3.4$ trillion, of which about $\$ 400$ billion corresponded to options. A Japanese exporter, for example, might buy dollar knockout put options, which expire prematurely if the dollar exchange rate drops below a certain level, to protect against a (moderate) depreciation of the dollar. But they provide protection only against moderate exchange rate changes and leave the investor unhedged against large currency movements, since as soon as the exchange rate breaches a certain level, the knockout option is canceled. In particular, the cancellation of complex options as the yen surged through several trigger levels and dealers' unwinding of hedges against these options, as well as the bunching of limit orders, created additional momentum that boosted demand for yen. Some temporary demand for yen appears to have originated from foreign investors who had short positions in Japanese stocks and decided to cover them ahead of new rules that bar investors from selling borrowed stock in declining markets. Thus a drop of the dollar large enough to trigger the cancellation of the option would expose the exporter to losses. In response, the exporter might be inclined to sell dollars into a falling market to cut his expected losses. As the dollar exchange rate fell, and knockout call options were canceled, dealers immediately sold the long dollar positions they held as a dynamic hedge for these options. So additional feedback in a falling market may have originated from the dynamic hedging strategies commonly employed by dealers who sell knockout options. The hedging of knockout put options typically involves more complex buying and selling of standard options as exchange rates vary. 
In a down market, standard put option values are bid up even higher by the dynamic hedging and expose dealers to significant losses. These reactions can contribute to an overshooting in the price (and implied volatility) of options.

The analysis above poses the question of whether there exist strategies that cointegrate prices and values and have bounded risk at the same time. From the point of view of a large player, a concern is excessive transaction costs linked with trading frequency. A common approach to ameliorate this problem is to use state dependent strategies, with a threshold for entering a hedging position, especially for a large trader, whose transaction costs are by far larger than for a price taker. By only entering a hedging position when the tracking error is large and exceeds a threshold, the goal is to hedge only when the expected price movement is large enough to beat transaction costs. Therefore the feedback hedging effect is only partial, restricted to a small part of the maturity of the derivative.

We introduce here a specific hedging criterion linked to a protfolio insurance strategy led by the large trader: she buyes puts only when the underlying asset falls under a given alarm level, if it remains there a certain period of time, and finally falls further down under a threshold level. Of course, depending on the risk aversion, the three previous parameters are likely to change.

We begin with a filtered probability space $\left(\Omega,\left(F_{t}\right)_{0 \leq t \leq T}, \mathbb{Q}\right)$ satisfying the usual conditions. $S_{t}$ is considered as the underlying asset price. To make calculations easier, a change of variable is introduced: $Y_{t}=S_{t}-s$. Thus, this threshold $s$ for $S$ is equivalent to the threshold 0 for $Y$. Under the risk-neutral martingale measure $\mathbb{Q}$, we know that the normalized prices of the traded securities follow a martingale

$$
\begin{aligned}
X_{t} & =Y_{t} \exp (-r t) \\
X_{t} & =\left(S_{t}-s\right) \exp (-r t) \\
d X_{t} & =f\left(\sigma_{t}\right) d W_{t} \\
X_{0} & =\left(S_{0}-s\right)=x
\end{aligned}
$$

Therefore, the threshold $s$ for $S$ is equivalent to the threshold 0 for $X$. We introduce several random times, representative of the three previously defined parameters of the partial hedging strategy :

- the random time corresponding to the last time that the hedging alarm threshold is hit:

$$
g(t):=\sup \left\{s \leq t: X_{s}=0\right\}
$$

- the random time corresponding to $\frac{\alpha^{2}}{2}$ time units spent under the hedging alarm threshold, which has to be determined by the large trader.

$$
\tau_{\alpha}:=\inf \left\{\begin{array}{c}
t>0: t-g(t) \geqslant \frac{\alpha^{2}}{2} \\
\text { where } X_{s} \leq 0 \forall s \in\left(g\left(t^{-}\right), t\right)
\end{array}\right\}
$$


- the random time corresponding to the hedging trigger threshold in order to limit losses, here as $S$ largely falls below the hedging alarm threshold.

$$
\tau:=\inf \left\{\begin{array}{c}
t>0: X_{t}=2 X_{\tau_{\alpha}} \\
\text { where } X_{s}<0 \forall s \in\left(\tau_{\alpha}, t\right)
\end{array}\right\}
$$

The doubling in absolute magnitude of the hedging alarm threshold is only for analytic convenience, but has no economic content. The generalization of this assumption is a subject for future research.

Random times properties We refer to the following Azéma-Yor theorem

Theorem $5 \tau$ has a $\mathcal{G}$-intensity, that is its predictive compensator $A$ is of the form

$$
A=\int_{0}^{t \wedge \tau} \lambda_{s} d s
$$

Furthermore

$$
\lambda_{t}=\left\{\begin{array}{c}
1_{\left[t>\tau_{\alpha}\right]} \frac{1}{2[t-g(t-)]} \forall t \epsilon[0, \tau] \\
0 \text { for } t>\tau
\end{array}\right.
$$

This theorem shows that the intensity of the hedging trigger threshold is zero until time $\tau_{\alpha}$ is reached. After time $\tau_{\alpha}$ it declines with the length of time that the firm remains under the alarm threshold without going below the hedging trigger threshold. The interpretation is that the longer the hedging trigger threshold is not reached, the less likely the hedging is to occur. Presumably, the underlying is more likely to recover, and may correspond to the signal of just a technical decrease and not a fundamental one.

European option pricing by the large trader Let

$$
\begin{aligned}
\operatorname{sign}(x) & =\{1 \text { if } x>0 ;-1 \text { if } x \leq 0\} \\
\tilde{\mathcal{G}}_{t} & : \quad=\sigma\left\{\operatorname{sign}\left(Y_{s}\right) ; s \leq t\right\}
\end{aligned}
$$

$\left(G_{t}\right)_{0 \leq t \leq T}$ denote the $Q$-complete and right continuous version of the filtration $\left(\tilde{\mathcal{G}}_{t}\right)_{0 \leq t \leq T}$.

Let $h\left(S_{T}\right)$ be the payoff of a European option. Consequently the hedging cost, under the state dependent threshold value scenario, is

$$
P_{t}=\mathbb{E}\left[\exp \left(-\int_{t}^{T} r_{u} d u\right) 1_{[\tau>T]} h\left(S_{T}\right) \mid \mathcal{G}_{t}\right]
$$

where $r_{u}$ is the instantaneous interest rate at time $u$ and $\mathbb{E}$ refers to the expectation under the Risk Neutral probability law. Lando has schown in the credit 
risk litterature that

$$
P_{t}=\mathbb{E}\left[\exp \left(-\int_{t}^{T}\left(r_{u}+\lambda_{u}\right) d u\right) h\left(S_{T}\right) \mid \mathcal{G}_{t}\right]
$$

To facilitate the evaluation of this expression, we will assume that interest rates are deterministic, thus

$$
P_{t}=\exp \left(-\int_{t}^{T} r_{u} d u\right) \times \mathbb{E}\left[\exp \left(-\int_{t}^{T} \lambda_{u} d u\right) h\left(S_{T}\right) \mid \mathcal{G}_{t}\right]
$$

Finally we can compute the conditional expectation, using Brownian motion excursion (details can be found in Protter (2004)), and Laplace transform:

$$
P_{0}=\exp \left(-\int_{0}^{T} r_{u} d u\right) \times\left(1-\left(\mathbb{E}\left[h\left(S_{T}\right) 1_{\left[\tau_{\alpha} \leq T\right]}\right]-\mathbb{E}\left[\frac{\alpha / \sqrt{2}}{T-\bar{g}_{\tau_{\alpha}}} 1_{\left[\tau_{\alpha}<T\right]} h\left(S_{T}\right)\right]\right)\right)
$$

\subsection{Taking into account the information asymmetry in dy- namic hedging strategies: the adverse selection com- ponent of the bid-offer spread}

The third category of costs is adverse selection costs. In our context, they arise from the fact that the large trader, in supplying immediacy, may trade with individuals who are uninformed about the expected price movement of the underlying security notably induced by the feedback hedging effect of the large trader. The links with feedback effect has been notably noticed by Easley and al. (1994), who showed that option market volume frequently leads stock prices because the option market is often the first venue for informed traders.

As a matter of fact, there are many kinds of information asymmetry between the large trader and the small traders

- the large trader is the only one who precisely knows the feedback effects of her own hedging strategy, inducing "feedback" volatilities that are either higher or lower than the usual one. Therefore she can use such an insider information to handle her gamma position by trading the spread between realized "feedback" and implied volatilities and to manage the volatility of volatility of her position through buying vega convexity.

- the large trader is precisely aware of the reaction function $\Psi$, which is specific to her portfolio strategy choice through the time interval $[0, T]$. In particular, she is the only one who knows the number of options held in her portfolio at each time $t$ and so the precise imbalance of her portfolio. Moreover, when she exercises her potions, she no longer hedges, so the 
underlying asset price dynamics may change drastically since feedback effects disappear, and the large trader is aware of this impact in pricing to the detriment of the small players. she is then able to undertake arbitrage strategies to the detriment of the small traders, with either European and American options. Moreover she may try to hide her transactions since she knows the parameters of her hedging strategy.

\subsubsection{Handling the gamma position by a large player}

Handling the long-term short gamma net position with long vega positions Due to the feedback effects of her hedging strategy, and to her structural long term short gamma position (being a net seller of options as often observed on the market), the large player may suffer a lot from rebalancing her delta position. In fact, if we consider the previous underlying dynamics

$$
\begin{aligned}
d \tilde{S}_{t} & =b\left(t, \tilde{S}_{t}\right) S_{t} d t+v\left(t, \tilde{S}_{t}\right) \tilde{S}_{t} d W_{t} \\
v\left(t, \tilde{S}_{t}\right) & =\frac{\sigma_{t}}{1-\rho \lambda\left(\tilde{S}_{t}\right) \tilde{S}_{t} \frac{\partial^{2} C}{\partial S^{2}}}
\end{aligned}
$$

the P\&L for a call with maturity $T$ (if we delta hedge using the usual fixed delta) is

$$
P \& L=C(T)-C(0)=\int_{0}^{T} \frac{1}{2}\left(v_{t(\text { real } i z e d)}^{2}-\sigma_{t(\text { sold })}^{2}\right) S_{t}^{2} \frac{\partial^{2} C}{\partial S^{2}}(t, S, \gamma) d t
$$

So we see that the outcome depends both on gamma and the difference between realised and hedge volatilities. So, in our situation where the gamma is negative, the P\&L depends on whether the realised volatility (over the hedging period) is lower than the estimated volatility used when writing the option. But a long-term short gamma position is equivalent to being net seller of options, which implies in our context a rise in volatility through the "feedback" effect induced by the large trader's hedging strategy. So the feedback effect goes in contradiction with the hedging strategy and increases the probability of a negative P\&L.

Thus the large player should compensate this loss by buying long term volatility, through long-term long option positions which are highly sensitive to the volatility, so that she could profit from the endogenous rise in volatility induced by her own hedging strategy. In fact, being the only one who is precisely aware of the feedback hedging effect on the volatility, that is her long-term short gamma position and the corresponding higher long-term volatility, she can buy long-term options, which are much more sensitive to changes in implied volatility than to moves in the underlying, priced with a lower volatility by the other players on the market. Then, if the option is bought at a volatility lower than the realized feedback volatility, the trade makes money. Among such options highly dependent on volatility to buy, we can mention: 
- out-of-the-money options which are more sensitive to volatility than atthe-money options. Then a rise in the volatility would benefit the holder, the large trader.

- variance swaps which increase linearly with respect to volatility. For example pricing such a product by changing the volatility parameter from $\sigma$ to $v\left(t, \tilde{S}_{t}\right)$ while using the same strike $V$ always induces a positive P\&L through the expected feedback effect. In fact the large player expects the payoff based on the feedback volatility that she aware of $\left(\int_{0}^{T} v^{2}\left(t, \tilde{S}_{t}\right) d t-\right.$ $V^{2}$ ) (in which $\int_{0}^{T} v^{2}\left(t, \tilde{S}_{t}\right) d t$ is obtained from the realised variance of the asset based on a list of fixing dates $t 0<t 1<\ldots<t n$ and $V$ is the fixed leg). whereas she buys a volatility swap based on a lower payoff with any small player $\left(\int_{0}^{T} \sigma_{t}^{2} d t-V^{2}\right) d t$, so the long-term short gamma position combined with the feedback effect should give rise to profits.

For example, with the calibrated parameters used above, $\lambda \rho=0.30$, the following initial skew structure matrix

\begin{tabular}{|cccccc|}
\hline Volatility & 80 & 90 & 100 & 110 & 120 \\
$01 / 09 / 2004$ & 32 & 30 & 29 & 28 & 26 \\
$01 / 10 / 2004$ & 33 & 31 & 30 & 29 & 27 \\
$02 / 03 / 2005$ & 34 & 32 & 31 & 30 & 28 \\
$01 / 09 / 2005$ & 35 & 33 & 32 & 31 & 29 \\
$01 / 09 / 2006$ & 36 & 34 & 33 & 32 & 30 \\
$31 / 08 / 2009$ & 37 & 35 & 34 & 33 & 31 \\
\hline
\end{tabular}

- fixings to calculate the realized volatility, and a spot $S=100$, the price rises up from 15.73 to 19.52 that is by $27 \%$.

Handling the short-term gamma position with long vega convexity position If volatility does trade higher or lower, it is likely that the volatility of volatility will jump as well. This will have the effect of compounding her gamma problem and her vega problem. Because the "feedback" volatility is either higher or lower than the usual one, the large trader can profit from such a vol of vol exposure by buying vega convexity or positive curvature with respect to volatility. Such a position gains in value if volatility either rises or falls, stemming from a switch of vega from short to long volatility as the implied volatility change. In fact with lower volatilities, a vega convexity position is short vega, getting shorter and shorter of volatility, and appreciates. With higher volatilities, the position becomes long vega and also appreciates.

In order to illustrate this phenomenon, let's look at the following structure: 1 year $100 \%$ straddle and 1 year 70-130 strangles. The graphs below vary the implied volatility. Whereas the straddle graph is almost linear and roughly proportional to the implied volatility, and thus has little vega curvature, the 
strangle graph is curved.

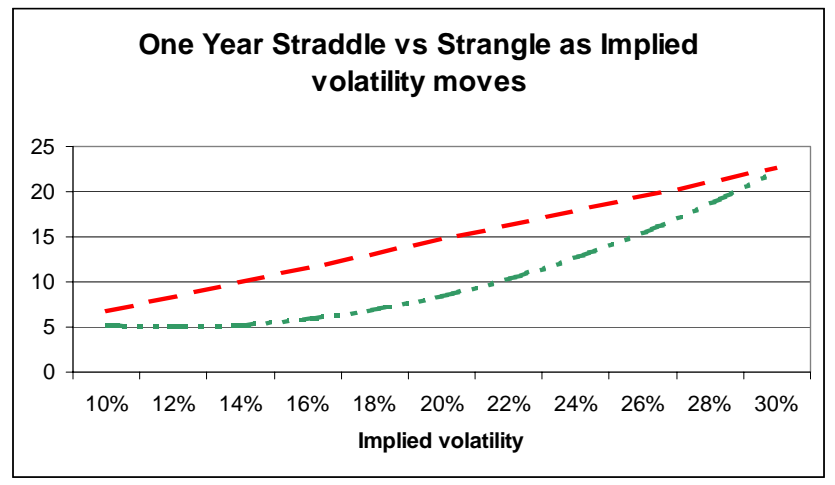

So the combination of a short straddle and a long strangle, although short volatility, is long vega convexity, as illustrated below

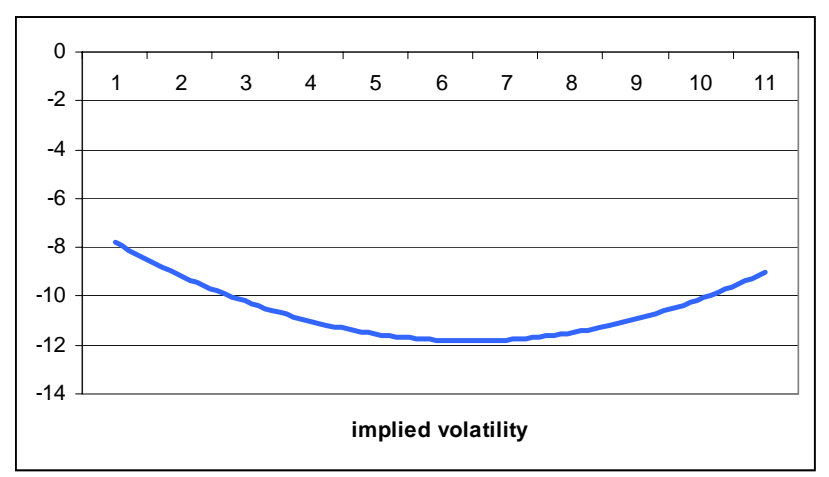

In fact any combination of ATM options and short OTM options has vega convexity, or volatility of volatility, even though the position itself is short volatility. Because of the relative richness of the OTM options versus the ATM options, we recommend buying ATM options versus selling OTM options. These can be put or call spreads, ratioed 1-1 or 1-2, combined to form a butterfly position: buy Put Spreads 1-1 (with low ATM vols and high OTM vol, cheaper than usual) and buy call spreads (same structure). Because the volatility of volatility is getting higher through the feedback effect, the variance swaps are more expensive relative to the at-the-money straddles, so one should buy variance swaps and sell at-the-money straddles in order to take advantage of the relative richness of the out-of-the-money puts relative to the at-the-money puts in buying vega convexity. Another long vega convexity position consists of buying variance swaps, which have positive convexity (because it pays off the volatility squared), and selling volatility swaps, linear with respect to volatility. So volatility swaps trade at a discount to variance swaps and the difference between looks like a straddle on volatility, which is a convex function of the volatility of volatility. New retail 
structure products that are simply long or short volatility are long volatility of volatility (or long vega convexity), such as Worst of Binary, CPPI structures, Capped Cliquets, Rainbow Calendar.

\subsubsection{Strategic dynamic hedging through inconspicuous portfolio hedg- ing strategies by a large player}

The large trader is the only one aware of her portfolio imbalance position (the number of options held in her portfolio at each time $t$ ), and also of the stop of the feedback hedging effect at the maturity of her options. Moreover she may try to remain undiscovered by the small traders, through inconspicuous hedging strategies ( i.e. such that the resulting underlying asset price process remains a Brownian motion under the risk-neutral measure), taking the feedback effect into account. She is then able to undertake arbitrage strategies to the detriment of the small traders, with either European and American options, based on the different strikes and maturities of her options portfolio.

We give various realistic financial examples of intertemporal portfolio strategies to the profit of the large trader in order to illustrate the importance of using such concepts in order to price European and American options in the case of full and increasing information asymmetry, using both the maturity effect (the large trader doesn't hedge any longer), the simultaneous and separate negotiations with different small traders, and the relative situation of the underlying asset price with respect to the strike.

Dealing with insider information Previously we put forward option pricing and hedging strategies with respect to the large trader's information: iIn fact we priced and hedged as if the number of options held by the large trader was given: even if the small traders manage to infer the form of the reaction function, they are unaware of the number of options (and thus of underlying assets) the large trader is willing to hold at each time. Therefore, as the underlying asset price and the option price depend on the number of options the large trader holds, the small traders can't properly price neither the option price nor the underlying asset price. In fact we can classify the agents in the market into two groups: uninformed traders and the informed trader (the large trader).

- uninformed (small) traders have no information about the feedback effect of future price of the underlying, and they can only observe the price ex-post. They have no market power and are not able to influence the dynamics of the underlying: their cumulative action result in a random walk, modellised by a standard Brownian motion $\left(W_{t}\right)$ under the risk neutral probability. In other words, under the forward-risk neutral probability 
associated to the bond numeraire (Geman and al 1995.)

$$
\begin{aligned}
\frac{d \widetilde{S}_{t}}{\widetilde{S}_{t}} & =\sigma_{t} d W_{t} \\
\widetilde{S}_{t} & =S_{t} E\left[\exp \left(-\int_{0}^{t} r_{u} d u\right)\right]=\frac{S_{t}}{B(t, T)}
\end{aligned}
$$

where $\widetilde{S}_{t}$ is the expected discounted underlying price with a stochastic interest rate $r$, which we take equal to 0 for simplicity of notation. As a result, the uninformed traders are called "noisy traders". Their information is based on the filtration $\left(F_{t}\right)_{t \in[0, T]}$

$$
F_{t}=\sigma\left(W_{s}, s \leq t\right)
$$

In the following, we always assume that the filtrations are completed and we use their right-continuous version.

- The large trader is considered as an insider by the knowledge of her market power. So she holds an improved information compared with the uninformed traders, because she is able to distinguish in the observed price what is linked to her specific impact linked to the hedging feedback effects: her filtration is larger than theirs. She knows that when she stops her "large trader behavior", the underlying price will retrieve its usual dynamics. Under the risk neutral probability in this particular filtration, the dynamics of the underlying is different:

$$
\begin{gathered}
\tilde{X}_{t}=\int_{0}^{t} \sigma_{s} d W_{s}+\int_{0}^{t} \rho_{s} \lambda_{s}\left(\tilde{S}_{s}\right) d \phi_{s} \\
\frac{d \widetilde{S}_{t}}{\widetilde{S}_{t}}=d \tilde{X}_{t}=\sigma_{t} d W_{t}+\rho_{t} \lambda_{t}\left(\tilde{S}_{t}\right) d \phi_{t} \\
\phi_{t}=\frac{\partial u(\gamma, t, \tilde{S})}{\partial \tilde{S}_{t}}
\end{gathered}
$$

is a semi-martingale which represents the number of underlyings held at time $t$ by the large trader to replicate the portfolio composed of $\gamma_{t}$ European call options, where $\eta_{t}$ is the number of options held by the large trader at time $t$, and $C_{t}$ is the option price at time $t$, solution of the feedback PDE.

Her information is based on the enlarged filtration

$$
\begin{aligned}
H_{t} & =F_{t} \vee G_{t} \\
F_{t} & =\sigma\left(W_{s}, s \leq t\right), G_{t}=\sigma\left(\widetilde{Z}_{t}\right)
\end{aligned}
$$


where the additional information flow $G_{t}$ is based on the fact that the discounted underlying price process comes back to its long term dynamics, i.e. driven by a continuous square-integrable Gaussian martingale with a deterministic volatility function $\sigma$

$$
\tilde{Z}_{t}=\tilde{Z}_{0}+\int_{0}^{t} \sigma_{s} d \bar{W}_{s}
$$

where $(\bar{W})_{0 \leq t \leq 1}$ is a Brownian motion, independent of $W$ under a suitable martingale preserving measure (see later).

Thus the resulting discounted underlying price

$$
\frac{d \widetilde{Y}_{t}}{\widetilde{Y}_{t}}=d \tilde{Z}_{t}=\sigma_{t} d \bar{W}_{t}
$$

Therefore, taking into account the feedback effect of her own dynamic hedging strategy, the large trader knows in advance the final underlying price at the maturity of her options: it will be determined by the underlying price without the presence of the large trader,

$$
\widetilde{Y}_{T}=\widetilde{S}_{T}
$$

independent of the action of the noisy traders.

We now introduce the way these two filtrations are linked as regards pricing, which will give rise to a spread between the pricing of small traders and the large trader: Under the so-called preserving probability measure under initial enlargement of Amendiger (1999), based on the usual Assumption (equiv.-[0,T]), saying just that at all times prior to $T$ the large trader has an informational advantage over the small traders, we can always consider that the signal, representative of the enlargement of filtration $G_{t}$, is independent of the filtration $F_{t}$, by which martingales under $F_{t}$ remains martingales under $H_{t}$.

Optimal inconspicuous dynamic hedging strategies The large trader is motivated to trade not only by making profits but also by a desire to protect the value of their inventory and disguise the quality of the information underlying their trades. So she adopts inconspicuous strategies in order to camouflage her trades. As a result, she is able to buy or sell the optimal quantity of options in such a way that the resulting underlying price remains a random walk, as it would be if the large trader weren't there, i.e. such that the resulting underlying price process $\widetilde{S}_{t}$ is again a Wiener process. Such strategies are called inconspicuous.

Case of full information The final underlying price at time $T$ is already known by the large trader from time 0 , so $G=\tilde{S}_{T}=\tilde{Y}_{T}$

Under the martingale preserving measure, the final signal $\widetilde{Y}_{T}$, which induces the additional information flow of the large trader, is independent of the Brownian motion $W$, representative of the activity of the uninformed traders. Using the same method as Back (1992) we can show that there exists an optimal 
equilibrium $\left(C, \gamma^{*}\right)$, based on three usual assumptions (market efficiency, profit maximization, equilibrium pricing rule) provided the final underlying price is normally distributed. In such a situation the optimal strategy for the large trader is given by

$$
\rho_{t} \lambda_{t}\left(\tilde{S}_{t}\right) \phi_{t}^{*}=\rho_{t} \lambda_{t}\left(\tilde{S}_{t}\right) \frac{\partial u}{\partial S}\left(\gamma_{t}^{*}, \tilde{S}_{t}, t\right)=\int_{0}^{t} \frac{\widetilde{Z}_{T}-\widetilde{X}_{s}}{T-s} d s
$$

from which we deduce $\gamma_{t}^{*}$, the optimal number of option to hold at time $t$ by the large trader. We can check that the resulting underlying price $\widetilde{S}_{t}$ forms a continuous centered squared-integrable Gaussian martingale with respect to its own filtration, so that the large trader is not discovered.

Case of increasing information The large trader obtains more information as time increases, by observing the signal process $\left(\widetilde{Z}_{t}\right)_{0 \leq t \leq T}$.

$$
G=\sigma\left(\widetilde{Z}_{t}\right)
$$

In fact, using the dynamics of the underlying in the absence of the large trader (and so using the information as time increases between time 0 and time $T$ ), which is the true one after time $T$, the large trader is able to hedge better, by a smoother strategy, reducing the size of the hedge ratios, hence minimizing the cost of hedging options. As a result this reduces transaction costs and reduces the possibility of being detected, since the resulted underlying price process is a Brownian motion with a smaller variance.

If the volatility function satisfies $\operatorname{var}\left(Z_{0}\right)+\int_{0}^{t} \sigma_{s}^{2} d s=1, \int_{0}^{t} \sigma_{s}^{2} d s<\frac{1-t}{1+\epsilon}$, for some constant $\epsilon>0$, then following the method of Wu (1999) we can show that

there exists an equilibrium with the same previous properties, $\rho_{t} \lambda_{t}\left(\tilde{S}_{t}\right) \frac{\partial u}{\partial \tilde{S}}\left(\gamma_{t}^{*}, \tilde{S}_{t}, t\right)=$ $\int_{0}^{t} \frac{\widetilde{Z}_{s}-\widetilde{X}_{s}}{\int_{0}^{1}\left(T-\sigma^{2}(u)\right) d u} d s$, from which we deduce $\gamma_{t}^{*}$, the optimal number of option to hold at time $t$ by the large trader.

\section{Strategic dynamic hedging examples}

Hedging European calls (maturity $T$ ) in the presence of hedging feedback effects From date 0, the large trader is aware of the fact that once her European option contract expires at time $T$, she stops hedging her option contracts. Therefore she knows that the dynamics of the underlying will retrieve its long trend after time $T$. So her additional information, represented by the filtration $G_{t}$, is generated by $\sigma(G)$, where $G$ is an $F$-measurable random variable with values in a Polish space $(X, X)$. So the large trader has the enlarged filtration

$$
H_{t}=F_{t} \vee \sigma\left(Z_{t}\right), t \in[0, T]
$$


In our context, and if we consider that the volatility is constant throughout the time interval $[0, T]$, the final underlying price $C_{T}$ at time $T$ is already determined by the outcome of some $N(0, T)$-distributed random variable $Z_{T}$ : although the underlying price process can be influenced by the trading activities of the large trader until the maturity of the European option, at the terminal time $T$ the underlying asset value at time $T$ is the intrinsic value, $\tilde{Y}_{T}$ and not $\tilde{S}_{T}$. Of course, thanks to her inconspicuous strategy, the two values will be the same, but from date 0 , she is the only one who is aware of this fact. Thanks to the preserving martingale measure, and with respect to the large trader's information, the value of the European option at time 0 equals

$$
C_{0}^{E u}=E_{Q_{T}^{G}}\left[C\left(0, \tilde{Y}_{T}, T\right)\right]=E_{Q_{T}^{G}}\left[\left(\tilde{Y}_{T}-K\right)^{+}\right]
$$

But the small traders are aware neither of the reaction function nor of the number of options held by the large trader, nor of the inconspicuous strategy. Therefore the reference price for negotiation may be completely different, at minimum equal to

$$
C_{0}^{\prime E u}=E_{Q_{T}^{G}}\left[\left(S_{T}-K\right)^{+}\right]
$$

and sometimes much higher than the required hedging price for the large trader, inducing an excess profit for the later. In fact, even if the small traders try to infer the feedback hedging effects from price observations, they will anticipate a higher underlying asset price at maturity $T$ because of the ill-assumed remained number of options $\phi_{T}$ held by the large trader (which actually equals zero under an inconspicuous strategy led by the large trader). Of course in that case they would take into account the fall in price implied by the liquidation of the large trader's portfolio, considering that the value of the underlying asset is only progressively going back to its fundamental value: the large trader would not be able to liquidate all her hedging stocks portfolio in a single trade at this price. In such a case, if they consider a strategy of liquidating in successive infinitesimal trades, the path from the value $\tilde{S}_{\tau}$ to the intrinsic value $\tilde{Y}_{\tau}$ would take some time, so the payoff of the option portfolio would be assessed by the small traders to be

$$
C_{0}^{\prime E u}=E\left[\int_{0}^{\phi_{T^{-}}}(\tilde{S}(T, x, 0)-K)^{+} d x\right]
$$

Such a mispricing would imply a net gain for the large trader if she contracts with them. So there is a spread

$$
C_{0}^{E u}-C_{0}^{\prime E u}=E_{Q_{T}^{G}}\left[\left(\tilde{Y}_{T}-K\right)^{+}\right]-E\left[\int_{0}^{\phi_{T^{-}}}(\tilde{S}(T, x, 0)-K)^{+} d x\right]
$$

to the profit of the large trader, who is the only one who knows that she will get into a portfolio strategy which will drive the underlying asset price towards 
the intrinsic value at time $T$. Therefore, thanks to this additional information, the large trader can better negotiate its European option contract.

Further details about other possible "selling large blocks" strategies are contained in Kalife (2002) who considers different market impact functions and devises a corresponding optimal selling strategy.

Exercising American calls (maturity $T$ and strike $K$ ) in the presence of hedging feedback effects For example, consider the situation where the large trader holds, at time $\tau, \gamma_{\tau}$ American call options which expire at time $T$, and where the underlying asset price remains under the strike for a long time, so the call is valueless. If the large trader is pessimistic, and if just before time $\tau$ the underlying asset price rises near the strike, she may profit from the situation by exercising her American call option: in fact, taking into account the next impact of her transaction (consisting of liquidating her underlying assets portfolio), thus buying back underlying assets, this would push the underlying asset price above the strike and thus making the call valuable. So there is an arbitrage opportunity, because the other small traders consider the past asset price dynamics, and not the real new one. So the other traders misprice the underlying asset price and thus the option price, because they don't hold the whole information. In fact, as the large trader exercises her American call options, she unwinds her replicating underlying assets portfolio, that is she buys back underlying assets, which pushes the underlying asset price upwards, because $\phi_{\tau^{-}}$is negative (she sells underlying assets as she buys call options) and progressively increases to zero. As a result, the liquidation value is higher than the mark-to-market value. So there is again a spread to the profit of the large trader.

Here we consider a large trader whose information is represented by the initial enlarged filtration

$$
G=\sigma\left(\widetilde{Z}_{t}\right)
$$

Pricing an American option amounts to finding the best exercising time, that is with respect to the large trader's information

$$
\begin{aligned}
\tau & =\arg _{t} \sup _{t \in[0, T]} E\left[V_{t}\left(\tilde{S}_{t}\right)\right] \\
V_{t}\left(\tilde{S}_{t}\right) & =\left(\tilde{S}_{t}-K\right)^{+}
\end{aligned}
$$

where $V_{t}$ represents the liquidation value of the replicating portfolio at time $t$ and $\tau$ is a random time on $(\Omega, H, P)$, i.e. a positive random variable, which represents the optimal time to exercise the American options. But remember that $\tau$ is a stopping-time only with respect to the large trader's information: it is a $H$-stopping-time, but not a $F$-stopping time. $\tau$ represents a specific passage time during the time interval $[0, T]$, such that the large trader would better exercise her option than wait, profiting from the impact of her transactions on the underlying asset price dynamics, and her decision depends here only on her 
specific situation, for example the strike or her portfolio structure, which is not known by the other traders.

Simultaneous buying and selling strategies in the presence of hedging feedback effects First we consider the case where all options traded have the same strikes and maturities. At time 0 we consider that the large trader transacts with two small traders: on the one hand she sells European calls, on the other hand she buys European calls. So the net option position is zero and the large trader doesn't need to hedge by a replicating portfolio in underlying assets. Therefore, because of the spread between the call bid and ask transacted prices with the two different small traders, the profit of the large trader is always positive. Actually, depending on the information of the two small traders about the holdings of the large trader, there is no longer a unique equilibrium price, but a continuum of no arbitrage prices. So the market is no longer complete .

Second we consider now the sale of one European call with maturity $T_{1}$, and the purchase of another European call with maturity $T_{2}$ with two different traders, the gain would be different than expected by the small traders : at time $T_{1}$ the number of options held by the large trader isn't zero, but equals the hedging ratio for the second option. Even if the first small traders is aware of the willing of the large trader to remain undiscovered, she is not aware of the large trader's holdings at time $T_{1}$, which will be negative (because the large trader will be long the second European call), and the first trader will overvalue the underlying asset price and thus option price from date 0 , to the profit of the large trader.

\section{Conclusion}

In this paper illiquidity has been introduced in the optimization of the large trader as an inability to trade and share risk without changing the market price.

Actually transaction costs and market slippage aspects of market liquidity risks have been isolated through a a parsimonious complete market model involving feedback hedging effects, which we integrated into a market framework and extended to give rise to an endogenously and empirically consistent bid-offer spread. Specifically, this model accounts for essential features of illiquidity: 1) Illiquidity trading costs are directly associated with the volatility of the spot price through the feedback effects, something that had to be assumed previously. 2) Illiquidity is also associated with the net volume generated by hedging pressures, a result common to the microstructure literature.

Then our approach emphasizes the empirical fact that illiquidity causes both hedging error troubles and strategic trading opportunities. Therefore we have devised specific practical partial hedging strategies used by practitioners, in order to reduce transaction costs, but to the detriment of a potential weaker hedge ratio. Moreover, taking the hedging feedback effect into account, the large 
trader is likely to use volatility derivatives and vega convexity strategies in order to compensate the gamma hedging costs. Finally, she may profit from her insider information, derived from both the specific structure of her options portfolio positions and the feedback hedging effect, through specific intertemporal hedging strategies to the detriment of small traders.

So we have devised specific hedging strategies used by practitioners in order to reduce hedging costs and to lead strategic trading using their insider information. As a result illiquidity has been naturally introduced in the optimization of the large trader as both an inability and an opportunity to trade and share risk.

\section{References}

[11], J. Amendiger, "Initial Enlargement of Filtrations and Additional Information in Financial Markets." PhD dissertation 1999.

[12], K. Back, "Insider trading in Continuous Time," Review of Financial Studies, 1992, (5), 387-409.

[6], J. Bierbaum, "Uber die Rückwirkung von Handelsstrategienausgewählter Investoren auf Wertpapierpreisprozesse." PhD dissertation 1997.

[8], C.T. Wu, "Construction of Brownian Motions in Enlarged Filtrations and Their Role in Mathematical Models of Insider Trading." PhD dissertation 1999.

Ane, T. and V. Lacoste, "Understanding Bid-ask Spreads of Derivatives under Uncertain Volatility and Transaction Costs," International Journal of Theoritical and Applied Finance, 2001, (3), 467-489.

Brennan, M. and E. Schwartz, "Portfomio Insurance and Financial Market Equilibrium," Journal of Business, 1989, (62), 455-472.

Chan, L.K.C. and J. Lakonishok, "Institutional trades and intraday stock price behavior," Journal of Financial Economics, 1993, (33), 173-199.

Delbaen, F. and W. Schachermayer, "A General Version of the Fundamental Theorem of Asset Pricing," Mathematische Annalen, 1994, (300), $463-520$.

Elliott, R.J., H. Geman, and B.M. Korkie, "Portfolio Optimization and Contingent Claim Pricing with Differential Information," Stochastics and Stochastics Reports, 1997, (60), 185-203.

Follmer, H. and M. Schweizer, "A Microeconomic Approach to Diffusion Models for Stock Prices," Mathematical Finance, 1993, (3), 1-23. 
Frey, R., "The Pricing and Hedging of Options in Finetely Elastic Markets," Working Paper, University of Bonn, 1996.

, "Perfect option hedging for a large trader," Finance and Stochastics, 1998, (2), 115-141.

__ , "Market volatility and feedback effects from dynamic hedging," preprint, 1999.

_ and P. Patie, "Risk management for derivatives with market illiquidities," 2001.

Gennotte, G. and H. Leland, "Market Liquidity, Hedging, and Crashes," American Economic Review, 1990, (80), 999.

Harrison, J.M. and J. Kreps, "Martingales and arbitrage in multiperiod securities market," J.Econ. Theory, 1979, (11), 418-443.

and S.R. Pliska, "Martingales and stochastic integrals in the theory of continuous trading," Stochastic Process. Appl., 1981, (11), 215-260.

Jacod, J., "Grossissement Initial, Hypothèse (H') et Théorème de Girsanov," Lecture Notes in Mathematics, Springer, 1985, (11), 15-35.

Jarrow, R., "Derivative Securities Markets, Market Manipulation and Option Pricing Theory," Journal of Financial and Quantitative Analysis, 1994, (29), 241-261.

, Protter P. Cetin U., and Yildirim Y., "Modeling Credit Risk with Partial Information," working paper, 2004.

Kalife, A., "Optimal Selling by a Large Player with non linear market impact," Working Paper,ESSEC, 2002.

Kambhu, J., "Dealers' Hedging of Interest rate options in the US dollar fixed income market," FederalReserve Bank of New York Economic Policy Review, 1998, (4), 35-57.

Keppo, J. and M. Jonsson, "Option pricing for large trader," Preprint, 2002.

Kim, J., K. Ko, and K. Noh, "Time-varying Bid-Ask Components of Nikkei 225 Index Futures on SIMEX," Working Paper, Korea Šs Security Research Institute, 2000.

Norden, L., "Asymmetric Option Price Distribution and Bid-Ask Quotes: Consequences for Implied Volatility Smiles," Working Paper,Stockholm University, School of Business, 2002.

Platen, E. and M. Schweizer, "On Smile and Skewness," Statistics Research Report 027-94 Australian University Camberra, 1998. 
Reinhard, H., Equations aux dérivées partielles, Dunod, Paris, 1987.

Schonbucher, P. and P. P. Wilmott, "The feedback effect of hedging in illiquid markets," SIAM Journal of Applied Mathematics, 2000, (61), 232272 .

Sircar, K.R. and G. Papanicolaou, "General Black-Scholes models accounting for increased market volatility from hedging strategies," Appl.Math.Finance., 1998, (5), 45-82.

Stoll, H., "Inferring The Components of The Bid-Ask Spread: Theory and Empirical Tests," Journal of Finance, 1992, (44), 115-134.

Stoll, H.R., "The pricing of security dealer services: An empirical study of NASDAQ stocks," Journal of Finance, 1978, pp. 1153-1172.

Stremme, A., "Pricing and Hedging od Derivative Securities : Some Effects of Asymmetric Information and Market Power." PhD dissertation 1999.

Vayanos, D., "Strategic Trading in a Dynamic Noisy Market," Journal of Finance, 2001, (56), 131-171.

Vijh, A.M., "Liquidity of the CBOR Options," Journal of Finance, 1990, (45), $1157-1179$.

Yoeurp, C., "Théorème de Girsanov généralisé et grossissement d'une filtration," Lect. Notes in Math. 1118, Springer, 1982, (118), 172-197.

Yor, M., "Grossissement d'une filtration et absolue continuité de noyaux," Lect. Notes in Math., Springer, 1985, (1118), 6-15. 